\title{
Informed choice or guessing game? Understanding caregivers' perceptions and use of infant formula labelling
}

Lenka Malek $^{1, *}$, Hazel Fowler ${ }^{2}$, Gillian Duffy ${ }^{3}$ and Lisa Katzer ${ }^{4}$

${ }^{1}$ Centre for Global Food and Resources, Faculty of the Professions, The University of Adelaide, Level 6 NEXUS 10 Tower, 10 Pulteney Street, Adelaide, SA 5005, Australia: ${ }^{2}$ Behavioural and Regulatory Analysis Section, Food Standards Australia New Zealand, Barton, ACT, Australia: ${ }^{3}$ Public Health Nutrition Standards, Food Standards Australia New Zealand, Barton, ACT, Australia: ${ }^{4}$ Labelling and Information Standards, Food Standards Australia New Zealand, Barton, ACT, Australia

Submitted 11 April 2018: Final revision received 28 September 2018: Accepted 15 0ctober 2018: First published online 27 November 2018

\begin{abstract}
Objective: Although breast-feeding is the recommended way to feed an infant, a safe and nutritious substitute for breast milk is needed for infants who are not breast-fed. Labelling information on infant formula (IF) products aims to enable caregivers (who have already made the decision to use IF) to make informed product choices. Yet, there is limited data on how caregivers understand and use the information provided on IF packaging. The present study aimed to increase understanding of caregivers' interpretation and use of the following label elements on IF products: the nutrition information statement; the ingredients list; and statements around nutrition content and health claims.

Design: Qualitative data were obtained from twenty-one focus group discussions. To enable comparison of findings by education level and ethnicity, focus group participants were homogeneous with respect to educational attainment (Australian groups) or ethnic background (New Zealand groups).

Setting: Focus groups were conducted in metropolitan and regional areas of Australia and New Zealand.

Participants: Caregivers ( $n$ 136) of formula-fed infants.

Results: Framework analysis revealed that caregivers commonly experience difficulties when using labelling information, particularly when trying to identify and understand key differences between products. Moreover, comparing products can be a complex task regardless of education level and ethnicity.

Conclusions: Further research is required to determine the most effective strategies for meeting information needs of caregivers and allowing easier identification and understanding of product differences. This is especially important given that the vast range of IF products across large price ranges in the market adds to the complexity of purchase decisions.
\end{abstract}

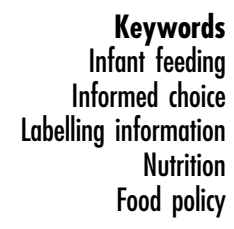

Although breast-feeding is the recommended way to feed an infant, a safe and nutritious substitute for breast milk is needed for infants who are not breast-fed. When infants are not breast-fed, infant formula (IF) is the only suitable and safe alternative ${ }^{(1)}$. Similar to other countries in the Organisation for Economic Co-operation and Development, in Australia and New Zealand (NZ) about $60 \%$ of infants will receive some IF by 3 months of age ${ }^{(1-3)}$. The Australia New Zealand Food Standards Code (hereafter, 'the Code') sets prescriptive composition requirements for IF products to ensure they are nutritionally adequate to promote growth and development when used appropriately. Regulated IF products include IF suitable from birth to $<12$ months, follow-on formula suitable from 6 months to $<12$ months, and IF products for special dietary uses suitable from birth for infants with a medical disorder or disease.

All IF products sold in Australia and NZ are subject to a range of labelling and packaging requirements and restrictions in the Code. These are designed to ensure the safe preparation, use and storage of IF, and to enable caregivers, who have already made the decision to use IF, to make informed choices when choosing between different IF products. Yet, relatively little research examines how caregivers use and understand the information provided on IF packaging. 
Many of the restrictions on the labelling, presentation and marketing of IF products aim to protect and promote breast-feeding in line with the WHO International Code of Marketing of Breast-milk Substitutes and its domestic equivalents $^{(4,5)}$. For example, labels must include the warning statement 'Breast milk is best for babies. Before you decide to use this product, consult your doctor or health worker for advice, ${ }^{,(6)}$. In Australia, manufacturers and importers of IF are signatories to the "Marketing in Australia of Infant Formulas: Manufacturers and Importers Agreement $1992^{,(7)}$. This voluntary self-regulatory code of conduct prohibits signatories from advertising and promoting IF products (for infants up to the age of 12 months) directly to the public. In NZ, the 'Infant Nutrition Council Code of Practice for the Marketing of Infant Formula in New Zealand' applies to IF suitable for infants up to the age of 6 months but currently excludes follow-on formula (suitable from 6 months) $^{(8)}$.

In 2016, there were more than twenty-five IF product lines in the Australian and NZ marketplace ${ }^{(9)}$. Some differences exist in the composition of products. For example, some products contain optional ingredients (permitted in the Code) and others do not. In addition, the composition may differ between formulas designed for different ages. Thus, the correct choice and use of IF is important for the health of infants. Infant feeding guidance in both Australia and NZ encourages caregivers to seek advice from health-care professionals when thinking about using an IF product. The Australian Infant Feeding Guidelines (hereafter, 'the guidelines') note that health workers have a responsibility to (where needed) educate and support caregivers with regard to using $\mathrm{IF}^{(10)}$. The guidelines support health workers providing general advice on choosing an IF (e.g. advising caregivers to use cows' milk-based formula). The NZ Code of Practice for Health Workers stipulates that 'Health workers should not promote a specific brand of formula, or be involved in the promotion of products used for infant feeding,(11).

Research suggests that caregivers do seek advice from health-care professionals on choosing an appropriate formula for their infant ${ }^{(12-15)}$. One of the most common topics formula-feeding caregivers report wanting more information on is the differences between different IF products $^{(12,14,16,17)}$. However, there is some evidence that suggests health-care professionals are reluctant to provide this advice ${ }^{(13,15,17,18)}$. Consequently, caregivers who are unable to or choose not to breast-feed can have difficulty obtaining information about formula from healthcare professionals ${ }^{(15)}$; and often report they rely on other sources of information, such as labels and the advice of friends and family, when choosing between products $^{(13,15,17)}$

Previous research on follow-on formula indicates that caregivers find it difficult to choose which IF product to purchase ${ }^{(15)}$. The IF product label can be a major source of information at the point of purchase ${ }^{(19,20)}$, and consumer studies on general food products reveal that inability to understand labelling information can impede informed product choice ${ }^{(21,22)}$. Irrespective of whether consumers choose to use food label information, key information required to make an informed choice should be provided in a manner that is easy to understand and can therefore be evaluated in the decision-making process if the consumer chooses. The existing literature shows that use of food labelling information can be driven by the goals/ motivations of the consumer or by the product itself (e.g. when the consumer's attention is drawn to specific labelling information due to size, colour scheme, familiarity with the label and/or its location on the packaging) ${ }^{(23)}$. Motivation to use food labelling information differs among consumers. In their conceptual framework, Jacobs et al. show that a consumer's motivation to use labelling information depends on a variety of internal influences (including sociodemographic and situational factors such as time constraints) and external influences (including food labelling regulation, role of food manufacturers and product attributes such as food label information, price and taste), which, in turn, influence the consumer's search for and understanding of labelling information and her/his subsequent evaluation and use of this information in the decision-making process ${ }^{(24)}$. Importantly, the ability to make an informed food product choice requires identification and understanding of key labelling information. Therefore, understanding how caregivers interpret and use elements of label information in selecting an appropriate IF product is important in developing the regulations for labelling requirements; at present, this information is lacking.

Most of the literature on understanding and use of food labelling information relates to general food products with which consumers typically have more experience in terms of purchase and consumption, rather than infant food products $^{(21,24-28)}$. The existing literature on the topic of formula decision making and awareness/use of labelling information is either from the USA ${ }^{(29)}$ or relates to followon formula or toddler milk (suitable for children aged 1-3 years) $)^{(15,30,31)}$. On the whole, caregivers of formula-fed infants are an understudied but important group as all infant feeding decisions (including selection of an appropriate IF product) can have health and safety implications. The present study therefore makes a valuable contribution to the limited existing literature on understanding and use of information on infant food labels.

The present exploratory study is a first step towards filling this knowledge gap. Specific study objectives were to determine how caregivers use and understand the following label elements when purchasing IF: the nutrition information statement (NIS), which lists quantities of various micro- and macronutrients per $100 \mathrm{ml}$ of prepared formula and is generally presented in table format; the ingredients list; and claims (e.g. nutrition content and health claims). Selection of these label elements was 
informed by a Food Standards Australia New Zealand (FSANZ) literature review ${ }^{(20)}$, which identified these as evidence gaps; and industry-funded market research submitted to FSANZ, which revealed a perception among some caregivers that claims on IF products provide useful information. The findings from the present study will help to inform a FSANZ review of the labelling requirements for IF products (in Standard 2.9.1) and are expected to have implications for formula-feeding caregivers, policy makers, health professionals, government health agencies and manufacturers of IF products.

\section{Methods}

\section{Study design}

Qualitative data were collected using focus group discussions conducted in metropolitan and regional locations in two Australian states (South Australia and Victoria) and in NZ. In Australia, metropolitan groups were conducted in Adelaide and Melbourne while regional groups took place in Mount Gambier and Ballarat. In NZ, metropolitan groups were conducted in Auckland and regional groups in Hamilton. Focus group methodology was selected for the ability to gain a comprehensive understanding of the range of views and experiences of participants more efficiently than in-depth interviews, which typically generate a large volume of in-depth data relating to specific participants $^{(32)}$.

\section{Stimuli}

Examples of commercial IF products were used as stimuli in the focus groups. Products were chosen to represent a mixture of products with variations in the claims they displayed and if they were portrayed as 'premium' or 'standard'. At the time of this research (early 2016) there were changes in the appearance of many IF labels on the market due to regulatory changes, which clarified the prohibition of nutrition content and health claims on IF products. This led to a reduction in the proportion of products carrying claims. This timing was considered an opportunity to examine how caregivers' perceptions of products with and without claims might differ. Consequently, the stimuli included a mixture of products produced prior to the regulatory change (which tended to carry claims) and products produced after the change (which tended not to carry claims).

\section{Participant selection and recruitment}

Purposive sampling was used for participant selection. The eligibility requirements for participants were: a caregiver of an infant aged up to 12 months; feeding IF or follow-on formula either exclusively or together with breast milk and/or solids; the primary decision maker regarding choice of IF product; aged 18 years or older; and able to speak English.
To ensure data were obtained on a broad range of views/experiences, four subgroups of participants were defined in each country, resulting in a total of eight subgroups (see Fig. 1). Two subgroups in each country were based on geographical location ('metropolitan' and 'regional'), and the other two subgroups were based on educational attainment in Australia and ethnicity in NZ. For the education subgroups, participants were categorised as either 'secondary education only' (SE; meaning they completed some or all of high school but had no qualifications beyond high school) or 'completed postsecondary education' (PSE; which included TAFE (technical and further education), vocational education and training, and university). For the ethnicity subgroups, participants were categorised as either: 'Maori/Pasifika ethnic background' or 'other ethnic background'. These subgroups were chosen to ensure a broad range of views/ experiences were obtained and, in the case of the education/ethnicity subgroups, to encourage an open and permissive group environment. This approach aligns with Krueger's view that homogeneity of focus group participants, with respect to factors which may influence sharing within the group discussion, can encourage group interaction and more open discussions ${ }^{(33)}$; although different views regarding best practice in terms of group composition and the need for homogeneity in focus group research do exist in the literature ${ }^{(34)}$.

Additionally, a mix of the following sociodemographic factors was aimed for in each group to ensure withingroup diversity: caregiver's age, ethnicity (for groups in Australia and Hamilton, NZ) and whether they were a firsttime $v$. subsequent caregiver. Target group size was eight to ten participants and data saturation for each subgroup was achieved after three focus groups, enabling comparison of findings between subgroups.

Recruitment was undertaken by professional research recruitment firms: Focus People (http://www.focus people.com.au) in Australia and Prime Research (http:// www.primeresearch.co.nz/focus-group) in NZ.

\section{Data collection}

A discussion guide (see online supplementary material) was developed based on the research objectives and a review of the relevant literature ${ }^{(15,30,32,35-37)}$. Importantly, the discussions focused on how caregivers use information on IF labels to choose between IF products once the decision to use formula has been made, rather than focusing on how caregivers decided to use IF in place of or in addition to breast-feeding. The discussion guide was pre-tested with three mothers in a one-on-one interview setting. While no issues were identified with the question wording during pretesting, one question was removed to avoid repetition of responses.

In addition to the focus group discussion, participants completed a brief self-report questionnaire which 


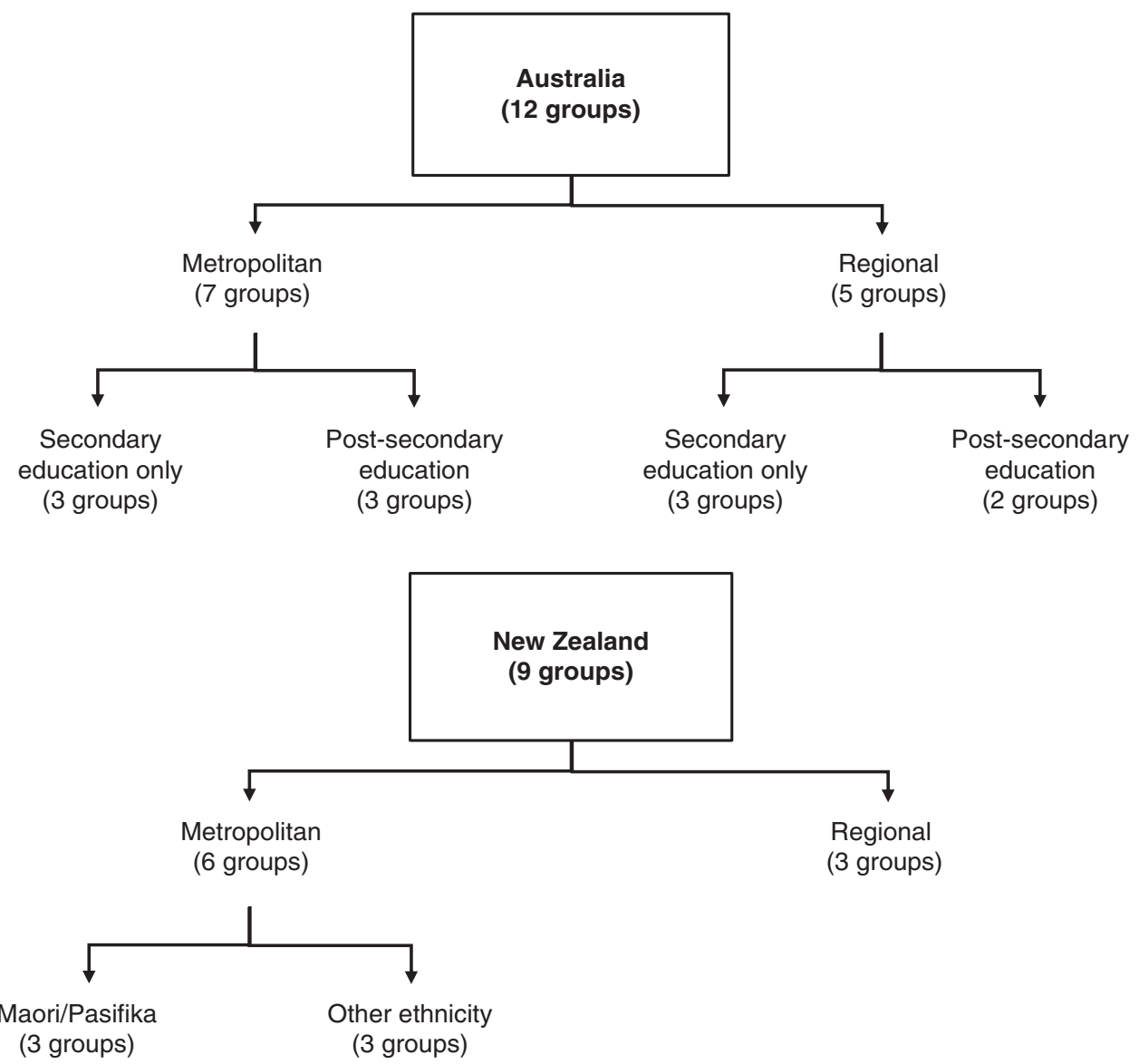

Fig. 1 Diagram showing the subgroups in each country and the number of focus groups per subgroup

collected information on gender, age, ethnicity, educational attainment, household income, employment status and household composition.

All focus groups were conducted during April and May 2016. Discussions were moderated by L.M. and a research assistant with training in interviewing techniques. Neither moderator had personal experience using or choosing between IF products. Discussions lasted between 38 and $76 \mathrm{~min}$, with longer duration generally reflecting higher levels of participant interaction. Discussions in metropolitan areas were conducted in private meeting rooms at the university or recruitment firm offices, and regional groups were conducted in hotel function rooms. All discussions were recorded with a digital voice recorder and transcripts were prepared by an academic transcription service. Ethical approval was obtained from the University of Adelaide Human Research Ethics Committee (HREC) prior to study commencement (approval number H-2016-057).

\section{Analysis}

Descriptive statistics were calculated for sociodemographic and household composition variables using the statistical software package IBM SPSS Statistics version 20.0. Focus group data were analysed using the framework approach, a method well suited for applied policy research $^{(38,39)}$. The five key steps followed when undertaking framework analysis are:

1. familiarisation, which involves immersion in the data by listening to recordings and/or reading the transcripts, and noting key ideas and recurrent themes;

2. identifying a thematic framework, which involves using both the data and the predetermined research questions to identify key ideas, concepts and themes to develop a framework for filtering and classifying/ coding the data;

3. indexing (or 'coding'), which involves closely examining the transcript and identifying/recording portions of text that correspond to the different themes identified in step 2;

4. charting, which involves taking the coded text from its place in the transcript and arranging it into charts (or 'matrices') of themes, where headings are based on the thematic framework identified in step 2; and

5. mapping and interpretation, which involves analysing the key characteristics presented in the charts according to the research objectives ${ }^{(38,39)}$.

The qualitative data analysis software NVivo version 10.0 (2012) was used to store the data (transcripts and audio recordings) and manage the coded text. After reading the transcripts (step 1 ) and developing categories 
Table 1 Characteristics* of caregivers of formula-fed infants ( $n$ 136) participating in focus group discussions on infant formula labelling in metropolitan and regional areas of Australia and New Zealand, April-May 2016

\begin{tabular}{|c|c|c|c|c|c|c|}
\hline & \multicolumn{2}{|c|}{ Australia ( $n 77)$} & \multicolumn{2}{|c|}{ New Zealand ( $n$ 59) } & \multicolumn{2}{|c|}{ Total $(n 136)$} \\
\hline & $n$ or mean & $\%$ or SD & $n$ or mean & $\%$ or SD & $n$ or mean & $\%$ or SD \\
\hline \multicolumn{7}{|l|}{ Focus group location } \\
\hline Metropolitan are & 46 & $59 \cdot 7$ & 37 & $62 \cdot 7$ & 83 & $61 \cdot 0$ \\
\hline Regional area & 31 & $40 \cdot 3$ & 22 & $37 \cdot 3$ & 53 & $39 \cdot 0$ \\
\hline Gender (female) & 74 & $96 \cdot 1$ & 58 & 98.3 & 132 & $97 \cdot 1$ \\
\hline Age (years), mean and SD & $32 \cdot 5$ & $6 \cdot 1$ & $28 \cdot 8$ & $5 \cdot 2$ & $30 \cdot 9$ & $6 \cdot 0$ \\
\hline \multicolumn{7}{|l|}{ Age group (years) } \\
\hline $18-24$ & 7 & $9 \cdot 1$ & 10 & $16 \cdot 9$ & 17 & $12 \cdot 5$ \\
\hline $25-29$ & 12 & $15 \cdot 6$ & 20 & 33.9 & 32 & 23.5 \\
\hline $30-34$ & 34 & $44 \cdot 2$ & 21 & $35 \cdot 6$ & 55 & $40 \cdot 4$ \\
\hline $35-39$ & 13 & $16 \cdot 9$ & 7 & 11.9 & 20 & 14.7 \\
\hline $40-44$ & 9 & 11.7 & 1 & 1.7 & 10 & 7.4 \\
\hline $45-49$ & 1 & $1 \cdot 3$ & 0 & 0.0 & 1 & 0.7 \\
\hline$\geq 50$ & 1 & 1.3 & 0 & 0.0 & 1 & 0.7 \\
\hline \multicolumn{7}{|l|}{ Highest education level } \\
\hline Secondary school only & 27 & $35 \cdot 1$ & 17 & $28 \cdot 8$ & 44 & $32 \cdot 4$ \\
\hline TAFE/vocational education and training & 23 & 29.9 & 24 & $40 \cdot 7$ & 47 & $34 \cdot 6$ \\
\hline Tertiary (university degree) & 27 & $35 \cdot 1$ & 18 & 30.5 & 45 & $33 \cdot 1$ \\
\hline \multicolumn{7}{|l|}{ Employment status } \\
\hline Full-time work & 12 & $15 \cdot 6$ & 6 & $10 \cdot 2$ & 18 & $13 \cdot 2$ \\
\hline Part-time work & 18 & 23.4 & 6 & $10 \cdot 2$ & 24 & $17 \cdot 6$ \\
\hline Full-time caregiver & 47 & $61 \cdot 0$ & 45 & $76 \cdot 3$ & 92 & $67 \cdot 6$ \\
\hline Full-time student & 0 & 0.0 & 2 & 3.4 & 2 & 1.5 \\
\hline \multicolumn{7}{|c|}{ Gross annual household income (\$AU and \$NZ) } \\
\hline$<25000$ & 2 & $2 \cdot 6$ & 10 & $16 \cdot 9$ & 12 & $8 \cdot 8$ \\
\hline $25001-45000$ & 8 & $10 \cdot 4$ & 19 & $32 \cdot 2$ & 27 & $19 \cdot 9$ \\
\hline $45001-65000$ & 8 & $10 \cdot 4$ & 9 & $15 \cdot 3$ & 17 & $12 \cdot 5$ \\
\hline $65001-85000$ & 16 & $20 \cdot 8$ & 9 & $15 \cdot 3$ & 25 & 18.4 \\
\hline $85001-105000$ & 21 & $27 \cdot 3$ & 6 & $10 \cdot 2$ & 27 & $19 \cdot 9$ \\
\hline $105001-125000$ & 8 & $10 \cdot 4$ & 2 & 3.4 & 10 & 7.4 \\
\hline $125001-145000$ & 7 & $9 \cdot 1$ & 3 & $5 \cdot 1$ & 10 & 7.4 \\
\hline$\geq 145001$ & 7 & $9 \cdot 1$ & 1 & 1.7 & 8 & 5.9 \\
\hline \multicolumn{7}{|l|}{ Ethnic background $\dagger$} \\
\hline Australian & 56 & $72 \cdot 7$ & 1 & 1.7 & 57 & 41.9 \\
\hline New Zealander, European descent & 1 & $1 \cdot 3$ & 27 & $45 \cdot 8$ & 28 & $20 \cdot 6$ \\
\hline New Zealander, Maori & 0 & $0 \cdot 0$ & 30 & $50 \cdot 8$ & 30 & $22 \cdot 1$ \\
\hline Southern and Eastern European & 6 & $7 \cdot 8$ & 1 & $1 \cdot 7$ & 7 & $5 \cdot 1$ \\
\hline North-West European & 20 & $26 \cdot 0$ & 6 & $10 \cdot 2$ & 26 & $19 \cdot 1$ \\
\hline Indian & 2 & $2 \cdot 6$ & 2 & $3 \cdot 4$ & 4 & $2 \cdot 9$ \\
\hline Chinese & 2 & $2 \cdot 6$ & 2 & 3.4 & 4 & $2 \cdot 9$ \\
\hline Other & 4 & $5 \cdot 2$ & 1 & $1 \cdot 7$ & 5 & $3 \cdot 7$ \\
\hline
\end{tabular}

TAFE, technical and further education.

*Data shown are $n$ and \%, unless indicated otherwise.

†Up to two options could be selected.

based on the study objectives (step 2), the transcripts were coded using the developed categories (step 3). For each label element (NIS, ingredients list and claims) a matrix was created (step 4): columns represented the different codes applied to the data, and rows contained relevant data from each focus group discussion. Once the coded data were synthesised in each cell of the matrix, it was interpreted (step 5), and the themes were reviewed and discussed by the authors until consensus was reached.

\section{Results}

\section{Participant characteristics}

A total of twenty-one focus group discussions were conducted with 136 caregivers of infants aged $<12$ months.
While one group comprised of two participants only, the remainder ranged in size from five to nine participants. Participants' sociodemographic characteristics and household composition data are presented in Tables 1 and 2, respectively. Overall, caregivers were aged between 18 and 57 years, with mean age lower in NZ. Compared with Australian caregivers, a higher proportion of NZ caregivers were in lower income categories $(\leq \$ N Z 45000)$, did not live with a partner, and had three or more children living at home. Similar proportions of Australian and NZ participants completed tertiary education and were first-time caregivers.

\section{Use and understanding of labelling elements}

A summary of themes identified across subgroups is provided in Table 3. Table 3 also shows the number of 
Table 2 Household composition of caregivers of formula-fed infants ( $n$ 136) participating in focus group discussions on infant formula labelling in metropolitan and regional areas of Australia and New Zealand, AprilMay 2016

\begin{tabular}{|c|c|c|c|c|c|c|}
\hline & \multicolumn{2}{|c|}{ Australia $(n 77)$} & \multicolumn{2}{|c|}{ New Zealand $(n 59)$} & \multicolumn{2}{|c|}{ Total $(n$ 136) } \\
\hline & $n$ & $\%$ & $n$ & $\%$ & $n$ & $\%$ \\
\hline Living with partner & 72 & 93.5 & 38 & 64.4 & 110 & $80 \cdot 9$ \\
\hline \multicolumn{7}{|c|}{ Relationship to infant aged $<12$ months } \\
\hline Biological parent & 75 & 97.4 & 57 & $96 \cdot 6$ & 132 & $97 \cdot 1$ \\
\hline Grandparent & 1 & $1 \cdot 3$ & 0 & 0.0 & 1 & 0.7 \\
\hline Adoptive parent & 0 & 0.0 & 2 & 3.4 & 2 & 1.5 \\
\hline Foster parent & 1 & 1.3 & 0 & 0.0 & 1 & 0.7 \\
\hline Primiparous (first birth) & 31 & $40 \cdot 3$ & 22 & $37 \cdot 3$ & 53 & $39 \cdot 0$ \\
\hline \multicolumn{7}{|l|}{ Infant's age } \\
\hline$\leq 6$ months & 25 & $32 \cdot 5$ & 16 & $27 \cdot 1$ & 41 & $30 \cdot 1$ \\
\hline 7-12 months & 52 & 67.5 & 43 & $72 \cdot 9$ & 95 & 69.9 \\
\hline \multicolumn{7}{|c|}{ Number of children ( $<18$ years) in household } \\
\hline 1 & 33 & $42 \cdot 9$ & 18 & $30 \cdot 5$ & 51 & $37 \cdot 5$ \\
\hline 2 & 30 & $39 \cdot 0$ & 19 & $32 \cdot 2$ & 49 & 36.0 \\
\hline 3 & 7 & $9 \cdot 1$ & 15 & 25.4 & 22 & $16 \cdot 2$ \\
\hline 4 & 6 & $7 \cdot 8$ & 3 & $5 \cdot 1$ & 9 & 6.6 \\
\hline$\geq 5$ & 1 & 1.3 & 4 & $6 \cdot 8$ & 5 & 3.7 \\
\hline
\end{tabular}

individual focus groups in which each theme was identified, providing an indication of the prevalence of specific themes/views within the sample. The themes are discussed in the sections below, with a selection of quotes representing the findings presented under relevant headings.

\section{Nutrition information statement}

Perceptions and understanding of the nutrition information statement. Several limitations of the NIS were highlighted by caregivers. One of the key issues raised in all subgroups (in more than half of the focus groups of SE and metro subgroups in Australia and the other ethnicity and regional focus groups in NZ) was the inability of caregivers to comprehend the nutrient content of IF products, mainly due to the absence of reference values (e.g. percentage daily intake). This also meant that comparison of nutrition information between products was generally useful only for determining which nutrients were included or absent in different products, as caregivers were not able to meaningfully interpret differences in nutrient values. Many caregivers also did not find the NIS very useful or informative because they did not know what the different nutrients were, the roles or benefits of the nutrients, and/or which nutrients were most important. This latter view was expressed in all subgroups and in more than half of the following focus groups: SE and regional in Australia and other ethnicity and regional in NZ.

'Just looking at it like that it doesn't mean a whole lot. It's just you don't know what the normal; a normal number would be for that particular thing.' (Australia, PSE, metro)
'Well, I read those for my food, but that's because I want to know the sugar and the salt and the fat in it, whereas this is showing all the good stuff, really, that's in it, and I don't know how much of that each day he's meant to get, so, it didn't mean, again, like the other, didn't mean anything to me.' (Australia, SE, metro)

Additionally, two caregivers in one of the Australian SE groups and one caregiver in one of the regional NZ groups stated that the long list of nutrients makes it difficult for them to compare nutrients across products. Further, three caregivers in another regional NZ group suggested and agreed the NIS should be simplified to make it more userfriendly, and specifically 'mummy-friendly'.

'I think it's too much information to be able to look at another tin and go oh, that one doesn't have that one, that one has that. It's just a huge list and there's going to be a huge list on the other tin. I can't tell which one's on that one and which one's not on that.' (NZ, regional)

Use of the nutrition information statement. The NIS was generally more useful and a stronger driver of product choice when caregivers were focused on specific nutritional requirements or health issues (e.g. when needing to increase infant's weight gain, correct micronutrient deficiencies or manage gut issues). The NIS was also often used to compare the nutritional content of premiumlabelled $v$. standard IF varieties. This comparison helps some caregivers decide whether it is worth paying more for the premium-labelled product. However, it was noted that nutrients present in premium-labelled products are often also observed in standard products, so differences were generally perceived to be minimal. Caregivers 
Table 3 Summary of themes identified across subgroups regarding the nutrition information statement, ingredients list and claims, in focus group discussions on infant formula labelling with caregivers of formula-fed infants ( $n$ 136) in metropolitan and regional areas of Australia and New Zealand, April-May 2016

\begin{tabular}{|c|c|c|c|c|c|c|c|c|}
\hline & \multicolumn{4}{|c|}{ Australia } & \multicolumn{4}{|c|}{ New Zealand } \\
\hline & $\begin{array}{l}\text { Secondary } \\
\text { education } \\
\text { only } \\
\text { (6 groups) }\end{array}$ & $\begin{array}{l}\text { Post- } \\
\text { secondary } \\
\text { education* } \\
\text { (6 groups) }\end{array}$ & $\begin{array}{l}\text { Metropolitan } \\
\text { (7 groups) }\end{array}$ & $\begin{array}{l}\text { Regional } \\
\text { (5 groups) }\end{array}$ & $\begin{array}{c}\text { Maori/ } \\
\text { Pasifika } \\
\text { (3 groups) }\end{array}$ & $\begin{array}{l}\text { Other } \\
\text { ethnic } \\
\text { background } \\
\text { (3 groups) }\end{array}$ & $\begin{array}{l}\text { Metropolitan } \\
\text { (6 groups) }\end{array}$ & $\begin{array}{l}\text { Regional } \\
\text { (3 groups) }\end{array}$ \\
\hline \multicolumn{9}{|l|}{ NIS } \\
\hline $\begin{array}{l}\text { Lack of information about nutrient } \\
\text { requirements limits meaningful } \\
\text { comparison of nutrition } \\
\text { information across products }\end{array}$ & 5 & 2 & 5 & 2 & 1 & 2 & 3 & 3 \\
\hline $\begin{array}{l}\text { Lack of nutrition knowledge } \\
\text { prevents use of NIS }\end{array}$ & 4 & 2 & 3 & 3 & 1 & 2 & 3 & 2 \\
\hline $\begin{array}{l}\text { Nutrition information is important } \\
\text { when infant has specific } \\
\text { nutritional requirements }\end{array}$ & 3 & 2 & 3 & 2 & 1 & 0 & 1 & 2 \\
\hline $\begin{array}{l}\text { Useful for comparing products, } \\
\text { e.g. premium-labelled } v \text {. } \\
\text { standard IF }\end{array}$ & 1 & 4 & 2 & 3 & 1 & 3 & 4 & 1 \\
\hline $\begin{array}{l}\text { Useful for checking sugar, fat } \\
\text { and/or salt content of IF }\end{array}$ & 2 & 2 & 2 & 2 & 2 & 0 & 2 & 1 \\
\hline $\begin{array}{l}\text { Long nutrient list makes product } \\
\text { comparison difficult }\end{array}$ & 1 & 0 & 1 & 0 & 0 & 0 & 0 & 1 \\
\hline $\begin{array}{l}\text { The more nutrients, the better the } \\
\text { formula }\end{array}$ & 1 & 1 & 1 & 1 & 0 & 1 & 1 & 1 \\
\hline It is a useful reference & 0 & 2 & 2 & 0 & 0 & 0 & 0 & 0 \\
\hline $\begin{array}{l}\text { Read out of interest by those who } \\
\text { want to know what is in IF }\end{array}$ & 0 & 1 & 0 & 1 & 2 & 0 & 2 & 0 \\
\hline $\begin{array}{l}\text { No need to check because all IF } \\
\text { products are healthy/safe/meet } \\
\text { standards }\end{array}$ & 0 & 2 & 2 & 0 & 1 & 1 & 2 & 0 \\
\hline \multicolumn{9}{|l|}{ Ingredients list } \\
\hline $\begin{array}{l}\text { Caregivers do not recognise or } \\
\text { understand the different } \\
\text { ingredients }\end{array}$ & 5 & 5 & 6 & 4 & 3 & 1 & 4 & 3 \\
\hline $\begin{array}{l}\text { Long list of ingredients can be } \\
\text { worrying or reassuring }\end{array}$ & 0 & 3 & 2 & 1 & 0 & 1 & 1 & 0 \\
\hline $\begin{array}{l}\text { Only check ingredients list if trying } \\
\text { to avoid specific ingredient }\end{array}$ & 4 & 3 & 3 & 4 & 2 & 3 & 5 & 3 \\
\hline $\begin{array}{l}\text { Trusting IF companies and } \\
\text { national standards }\end{array}$ & 1 & 4 & 3 & 2 & 0 & 0 & 0 & 1 \\
\hline \multicolumn{9}{|l|}{ Claims } \\
\hline $\begin{array}{l}\text { Do not understand nutrient claims } \\
\text { which show nutrient names/ } \\
\text { acronyms }\end{array}$ & 6 & 6 & 7 & 5 & 3 & 2 & 5 & 3 \\
\hline $\begin{array}{l}\text { Claims usefully summarise and } \\
\text { simplify the ingredient and } \\
\text { nutrition information }\end{array}$ & 1 & 3 & 3 & 1 & 1 & 1 & 2 & 0 \\
\hline $\begin{array}{l}\text { Claims in sentence form and } \\
\text { stating health benefits are } \\
\text { easier to understand than } \\
\text { claims showing nutrient names } \\
\text { or acronyms }\end{array}$ & 3 & 6 & 5 & 4 & 3 & 2 & 5 & 3 \\
\hline $\begin{array}{l}\text { Claims are a marketing strategy } \\
\text { and can't always be trusted }\end{array}$ & 2 & 4 & 5 & 1 & 0 & 2 & 2 & 2 \\
\hline \multirow{2}{*}{$\begin{array}{l}\text { Some claims are particularly } \\
\text { appealing }\end{array}$} & 4 & 4 & 3 & 5 & 2 & 3 & 5 & 2 \\
\hline & $\begin{array}{l}\mathrm{FO}(3) \\
\mathrm{IM}(1) \\
\mathrm{BM}(1)\end{array}$ & $\begin{array}{c}\text { FO (1) } \\
\text { IM (1) } \\
\text { BD (1) } \\
\text { DG (1) } \\
\text { Sleep (1) }\end{array}$ & $\begin{array}{l}\mathrm{FO}(2) \\
\mathrm{IM}(1) \\
\mathrm{BD}(1)\end{array}$ & $\begin{array}{c}\text { FO (2) } \\
\text { IM (1) } \\
\text { BM (1) } \\
\text { DG (1) } \\
\text { Sleep (1) }\end{array}$ & $\begin{array}{l}\mathrm{FO}(1) \\
\mathrm{IM}(1) \\
\mathrm{HB}(2)\end{array}$ & $\begin{array}{l}\text { IM (3) } \\
\text { BD (2) } \\
\text { DG (1) } \\
\text { BM (2) } \\
\text { HB (2) }\end{array}$ & $\begin{array}{l}\text { FO (1) } \\
\text { IM (4) } \\
\text { BD (2) } \\
\text { DG (1) } \\
\text { BM (2) } \\
\text { HB (4) }\end{array}$ & $\begin{array}{l}\text { BD (1) } \\
\text { IM (1) } \\
\text { DG (1) } \\
\text { BM (2) } \\
\text { HB (2) }\end{array}$ \\
\hline $\begin{array}{l}\text { Claims reduce guilt associated } \\
\text { with using IF }\end{array}$ & 0 & 1 & 1 & 0 & 0 & 1 & 1 & 2 \\
\hline
\end{tabular}

NIS, nutrition information statement; IF, infant formula; BD, brain development; IM, immunity/immune system; FO, fish oil; DG, digestion/'gentle on tummy'; Sleep, 'sleep better' and 'full tummy'; BM, 'closest to breast milk' or 'good as a breast-milk substitute'; HB, 'for hungrier babies'.

Data shown without parentheses are the number of individual groups in which themes were identified. Data shown in parentheses are the number of individual groups in which specific claims were identified as appealing.

${ }^{*}$ Post-secondary education includes TAFE (technical and further education), vocational education and training, and university. 
generally reported finding this nutrient comparison easy, especially when nutrients are listed in the same order.

'But, to be honest, who understands that? Like, you know, in reality, like, unless you are really into your nutrition or there - maybe something is wrong with your baby, like they have a slight allergy to, maybe, a cow protein or something, you're really not going to know what any of that means.' (Australia, PSE, regional)

Some caregivers (in all subgroups except NZ other ethnicity) reported checking the sugar and often salt and/ or fat content of IF products as these are the nutrients they check when purchasing food for personal consumption. One caregiver stated that she does not purchase IF products that contain added sugar 'because it's supposed to be pure milk', while others experienced difficulty determining the sugar content of IF products, reporting that sugar is often 'disguised as different names'. Notably, IF composition is prescribed by the Code and carbohydrate is a mandatory component of energy in IF. In cows' milk-based IF products, the naturally occurring sugar, lactose, is the carbohydrate source, and in soya and specialty formulas, glucose syrup often provides the carbohydrate. Further, sodium is an essential electrolyte and must be present within a specified range. While carbohydrate and sodium must be declared in the NIS, sugar (sucrose) need not be.

In some cases, caregivers preferred IF products listing a larger range of nutrients (e.g. 'whatever's got the most writing on it [laughs] is what I think is better'), as they believed these products would meet a wider range of nutrient requirements; and products with less nutrition information are less nutritious because they would otherwise be advertising the additional nutrients present. This view was expressed by at least one participant in one focus group across all subgroups. In addition, one NZ caregiver (other ethnicity subgroup) who judges the quality of IF products based on the appearance of the packaging, stated that a long list of nutrients could in some cases redeem a 'cheap and nasty looking' product. Notably, while the Code requires the NIS to contain certain nutrients, manufacturers may choose to list additional nutrients. Thus, the number of items included in the NIS is not necessarily an indication of the number of additional nutrients voluntarily added by the manufacturer.

Three Australian caregivers (across two PSE/metro focus groups) acknowledged that the NIS is useful as it provides the opportunity to further 'research the nutrition information' at a later time if needed. Another three caregivers (in one PSE/regional group and two Maori/ metro groups) acknowledged they liked to look at the nutrition information out of interest, 'just to know what's in it'. In contrast, six caregivers (in two PSE/metro, one Maori and one other ethnicity/metro groups) did not feel a need to check the NIS as they believed that IF products would not be on the market if they were not 'healthy', 'safe' or 'approved by health authorities'. The two Australian caregivers assumed or were aware that IF is regulated and has to meet certain standards, with one caregiver basing this assumption on her awareness of the 'nutritionally complete' statement found on formula company websites.

'I don't really read it because I just don't read it. I just trust the fact that it's a product that my kid can have. It's on the shelves so it must be all right.' (NZ, other ethnicity, metro)

'I think because it's so like how Australian formula or even the formulas coming from Germany or wherever, they're so strict on how they produce the formula that there are so guidelines on what they're putting into the formula and what they have to that there's not much difference between each one.' (Australia, PSE, metro)

\section{The ingredients list}

Perceptions of the ingredients list. A few caregivers (at least one caregiver in 3/6 PSE metro and regional groups and one NZ other ethnicity caregiver) found long ingredients lists 'worrying', 'scary' or 'off-putting', especially as they often did not know what many of the ingredients were. Two of these caregivers (PSE/metro and other ethnicity) expressed that sometimes 'ignorance is bliss', acknowledging they would rather not be aware of the long list of ingredients in the formula. One caregiver specifically tried to ignore all ingredients apart from protein, as she felt guilty for using formula and did not want to know what else was in the product. In contrast, long ingredients lists were viewed favourably by two Australian caregivers (in $2 / 6$ PSE groups, metro and regional) as they give the impression that the formula contains everything that the infant requires; this was believed to be especially important when formula was the infant's sole food.

'It's good to see it and to see that there is a whole lot of things in it, because that's what you want. It's meant to be like an all in - like, that's all they're eating to start with. So you want everything in it. So you sort of get the tin and you're like, yep, heaps of ingredients; okay, it's probably got it all in there. But you don't actually go through each one and go has it got whatever? Well, I didn't anyway.' (Australia, PSE, regional)

Use of the ingredients list. In most focus groups (across all subgroups), caregivers reported that they would only read the ingredients list if they had a reason, with main reasons including their infant needing to avoid specific ingredients for health reasons or hearing about specific ingredients in the media. For example, participants who 
reported using the ingredients list when choosing between products generally had an infant with an allergy or intolerance. The Code mandates the declaration of specific food allergens, although the location of these declarations is not specified.

Two Australian caregivers (in two SE/metro groups) also reported they would check the ingredients list if their child was not reacting well to formula and they wanted to identify potential causes. Additionally, two NZ caregivers (in one regional and one other ethnicity/metro group) felt this information was particularly useful when parents wanted children to follow specific diets such as vegetarian or vegan diets. Reports of using the ingredients list to search for specific desirable ingredients were limited to two caregivers (SE/metro and other ethnicity/metro) who reported looking for 'omega' and 'fish oil'.

'I guess because my son personally isn't allergic to anything so far I haven't looked at a, "I don't want to have this or this or this". So I've just gone with whatever's in it I guess.' (NZ, other ethnicity, metro)

Barriers to using the ingredients list. Caregivers often did not read the ingredients list because they did not recognise many of the ingredients. Consequently, the ingredients list tended to be described as 'a lot of mumbo jumbo' or 'jargon'; with the following often stated, 'I don't know what half of these things are'. However, despite not knowing what the ingredients are, three caregivers (in one $\mathrm{SE} /$ regional, one Maori and one regional NZ group) reported reading the list out of curiosity, to get an idea of what is in the formula, and for product comparison.

Other reasons for not reading the ingredients list or not finding it useful were: lack of awareness of the ingredients list; not understanding the difference between the ingredients list and NIS; and lack of time, specifically not having time to stand in the shop and read the entire list or not having the time to research (usually Google) all of the unknown ingredients. Three caregivers (in two PSE/metro groups and one other ethnicity/metro group) also noted that while they may not read the ingredients list before purchasing the product, they might refer to it later (e.g. if they want to check/research some of the ingredients).

'When you're in the supermarket and you got kids, you don't want to piss around reading ingredients to put it mildly.' (NZ, regional)

'I think the ingredient ( $\mathrm{sic}$ ) is a bit hard to know what's actually in it. So if you're just at the supermarket looking at it, you like have no idea without physically looking up exactly what the ingredients are. So I think the recommendations of other people kind of have more weight. (...) I do like that they have it though, because if you want to do the research you can look it all up. But I wouldn't, probably, but it's there if I want to, so it's transparent.' (Australia, PSE, metro)
Additionally, some caregivers (across all Australian subgroups and in one regional NZ group) admitted that they never thought to check the ingredients list as they trusted that the formula company 'knows what they're doing' and is 'making formula right for the baby'. Similarly, others pointed out that they were not concerned about the ingredients as all formula available on the market must meet certain standards.

\section{Claims (e.g. nutrition content and health claims)}

Two types of claims were discussed in the focus groups. The first type were nutrition content claims which indicate the presence or quantity of a particular nutrient/ingredient (such as 'contains $\mathrm{x}$ ' or 'high in $\mathrm{x}$ '). The second type, health claims, link the presence of a nutrient to a beneficial health effect (e.g. 'contains calcium for strong bones').

Understanding and use of claims. There was widespread acknowledgement by caregivers (in all subgroups and all individual focus groups apart from one 'other ethnicity' focus group) that they do not understand the nutrition content claims (names or acronyms) and consequently 'just glaze over those', or think the words are 'just gibberish', 'jargon' or 'in Morse code'. Caregivers who do not understand nutrient content claims do not consider them relevant when choosing between formula products. In multiple focus groups for each subgroup, caregivers reported that health claims were easier to understand and more meaningful than nutrition content claims, as the nutrients and benefits are explained in sentence form. Further, it was believed that explaining the scientific names/acronyms using simple 'layman's' terms would allow the information to be understood by those without a scientific background and who may be sleep-deprived. Two caregivers (PSE/metro and Maori) also suggested the benefits could be conveyed more visually (using pictures).

'I don't really understand what a lot of that stuff is, so, therefore it wasn't really relevant to me. I kind of looked at that and it was a bit more just blank, I don't even know what DHA is, or yep.' (Australia, SE, metro)

Some caregivers viewed the claims as a marketing strategy, reporting they were not influenced by them or placed little weight on them when making purchase decisions. This view was expressed by at least one caregiver in multiple focus groups for all subgroups except regional Australia, where it was expressed in one group only, and in Maori, where it was not expressed in any groups. Four caregivers (in three PSE/metro groups and one other ethnicity/metro group) also highlighted, and others agreed, that many IF products make similar claims or suspected there are few real differences between products. Reasons for this scepticism included lack of awareness or understanding of the supporting evidence for the claims and/or the benefits conferred by the additional nutrients/ingredients. One NZ caregiver (other 
ethnicity) also questioned whether the claimed nutrients/ ingredients are present in breast milk and, therefore, whether their presence in formula is warranted; and, if yes, is there an optimal amount. Further, two caregivers (Australian SE/metro and NZ regional) highlighted, and others agreed, they are less likely to trust products that make multiple claims. They felt there is no guarantee the formula will provide all the claimed benefits, and if the product makes too many claims, they wonder what the labelling is 'trying to prove'.

'You take it on board but the clever marketing, you know, people can spin things to make them sound better than the one next to it, even though it's probably the same in a lot of respects so, like, I read it but I wouldn't make a decision on formula based on the claims or anything like that because they're paid the big bucks to be able to make you think that theirs is better than the next one so...' (Australia, PSE, metro)

Despite most caregivers (multiple caregivers in all focus groups apart from one regional NZ group) admitting to not understanding claims, it was often noted claims are useful as they provide an overview of the main benefits of, or nutrients in, the formula. Caregivers in all subgroups apart from regional NZ tended to find claims easier to understand and more meaningful than the ingredients list or NIS. Caregivers explained that, by simplifying the nutrition information, claims help them understand what is in the formula. NZ groups noted this was particularly important when caregivers are sleep-deprived, have a screaming baby and/or do not have time to read everything on the label. It was also noted that the placement of claims on the front of the package makes them stand out more than information in the NIS or ingredients list. Additionally, claims were sometimes used to narrow down product choices, after which other labelling information may or may not be read depending on time constraints.

'Plus, we don't understand what, you know, a lot of the big words and the ingredients are and what they do. That kind of tell us what those are. (...) Yeah and that just narrows it right down hey. (...) It puts it in English.' (NZ, regional)

'And all the scientific jargon is usually, when that's mentioned, it actually means that it was tested and, you know, there's this proof and evidence that it works. So whether, I think it's just marketing strategy, but I've actually just looked at and I believe it, because...' (Australia, SE, regional)

Caregivers in multiple focus groups across all subgroups reported searching for specific claims or finding specific claims particularly appealing. Influential claims included those that refer to: immunity (all subgroups), fish oil (6/8 subgroups), brain development (5/8 subgroups), digestion/being gentle on tummy (5/8 subgroups), 'sleep better' and 'full tummy' (2/8 subgroups, Australia only), and 'hungrier babies' (all NZ subgroups). Participants noted that immunity is often flagged as a key benefit of breastfeeding, and they interpreted 'immunity' claims to mean their infant can receive these benefits even though they are not breast-feeding. Products with statements such as 'closest to breast milk' or 'good as a breast-milk substitute' were also appealing to a few caregivers in 5/8 subgroups. Notably, statements referring to the nutritional content of breast milk, including comparisons between breast milk and IF, are prohibited by the Code.

'I get sucked in by the brain development thing. I don't know if it's true or not, but I get sucked in.' (Australia, SE, metro)

'I like to, I always like to see like "best breast-milk substitute". Like whether it's good as a breast-milk substitute or not because if it doesn't mention that then I don't buy it anyway regardless of what price it is.' (NZ, regional)

For some caregivers (three across PSE/metro, other ethnicity/metro and regional NZ groups), the claims on IF products reduced the guilt associated with using formula. They explained that the claims 'didn't make formula seem so bad' and provided reassurance that even though they were not breast-feeding, their infant would still benefit from consuming the IF product. In particular, one regional NZ caregiver acknowledged claims about 'best breast-milk substitute' were a strong driver of product choice as it alleviated her guilt about choosing to formula-feed rather than breast-feed; and one Australian caregiver (PSE/ metro) stated the claims on IF products motivated her to use formula to top up breast-feeds. This suggests that claims on formula may encourage some women to use formula to supplement breast-feeding, when they might not have otherwise.

'I think when I first chose a formula I was feeling quite guilty about buying it. It wasn't my intention to ever buy it that quickly and I think some of those statements probably made me feel better about what I was doing. I don't really understand them, but it probably made me feel better, well it can't be that bad.' (Australia, PSE, metro)

\section{Key differences between countries and subgroups}

Australia v. New Zealand

All themes/views arose in both Australian and NZ focus groups, apart from the view that the NIS is a useful reference for checking later, which was expressed by Australian caregivers only.

\section{Metropolitan v. regional}

In both countries, the view that there is no need to check the NIS because all IF products are healthy/safe/meet 
standards was expressed in the metropolitan subgroup only. The view that the long nutrient list makes product comparison difficult was also expressed only in the metropolitan groups. In contrast, the theme of reading the NIS out of interest to find out what is in IF was expressed only in the regional subgroups.

\section{Secondary education only v. post-secondary education}

The following were expressed by PSE caregivers only: the NIS is a useful reference, is read out of interest by those who want to know what is in IF, and does not need to be checked because all IF products are healthy/safe/meet standards; long lists of ingredients can be worrying or reassuring; and health/nutrient claims reduce the guilt associated with using IF. The only view that was expressed exclusively by SE caregivers was that long nutrient lists make product comparison difficult.

\section{Maori/Pasifika v. other etbnicity}

The following were expressed by Maori/Pasifika caregivers only: the nutrition information is important when an infant has specific nutritional requirements; the NIS is useful for checking sugar, fat and/or salt content of formula; and the NIS is read out of interest by those who want to know what is in IF. In contrast, the following views/themes arose in the other ethnicity subgroup only: the more nutrients, the better the formula; a long list of ingredients can be worrying; claims are a marketing strategy and can't always be trusted; and claims reduce guilt associated with using IF.

\section{Discussion}

The present study offers new insight into how formulafeeding caregivers perceive, understand and use elements of labelling information on IF products when making purchase decisions. Consistent with previous research on follow-on formula ${ }^{(15)}$, we show that caregivers are interested in differences in the nutritional content of products, yet they commonly experience difficulties when using labelling information (particularly the NIS and ingredients list) to identify and understand key differences between IF products. Some participants noted they lacked the knowledge to meaningfully interpret the information presented in these labelling elements and therefore do not find them useful when making purchase decisions. In addition, some caregivers use information in the NIS and ingredients list to make decisions based on criteria that may not be helpful for choosing between products. For example, some caregivers report attempting to choose products lower in sugar, salt or fat without understanding that the quantities of these nutrients are strictly regulated and quite different from those in general foods.

Our findings show that the NIS and ingredients list tend to be most useful to caregivers who are seeking a formula that meets specific dietary requirements (i.e. seeking information on specific nutrients/ingredients). We further reveal that inability to meaningfully interpret the NIS and ingredients list leads some caregivers to use any nutrition content or health claims as a quick and easy summary of the ingredients and nutrition information. This suggests that caregivers are generally able to identify key information and make simple comparisons when they have a clear purpose for using the nutrition/ingredient labelling information but otherwise find it difficult to meaningfully interpret this information. This is consistent with Cowburn and Stockley's review, which showed that consumers' understanding and use of nutrition labelling on general food products depend on the purpose and complexity of the task ${ }^{(27)}$. That review also highlighted that interpretational aids (e.g. verbal descriptors and recommended reference values) can assist consumers with product comparison $^{(27)}$. Additionally, our findings also support recent US research showing that many IF labels (similar to health education materials) have high reading demands and poor layout ${ }^{(40)}$. Overall, this suggests that education and/or additional information sources about the basis of the essential composition of IF could assist with improving caregiver understanding of nutrition/ingredient labelling.

Label formatting amendments could also improve the ability to compare products, with previous research showing that the format of nutrition information on general food products has strong, significant effects on nutrition attitude and purchase likelihood ${ }^{(41)}$. Previous FSANZ research shows consumers believe that presentation of nutrients in a consistent order in the nutrition information panel on all foods is important, in addition to using consistent terminology to describe nutrients ${ }^{(42)}$. Unlike on general foods, the format and layout (e.g. wording and placement) of nutrition information on IF is not mandated in Australia and NZ. Mandating the order or layout of the NIS could improve the ability of Australian and NZ caregivers to identify product differences; although further research would be required to test the effectiveness of specific changes.

The finding that claims help to alleviate some of the guilt associated with formula-feeding and motivated some caregivers to use formula for top-up feeds while continuing to breast-feed, supports the idea that claims on IF products can create a 'health halo' effect. This is consistent with the literature related to general foods, showing that products carrying health claims are perceived by consumers to be healthier, and this perception can discourage consumers from searching for additional nutrition information $^{(43)}$. It is important to note that some of the IF products selected as stimuli for the present study carried claims and were in the marketplace prior to regulatory changes that strengthened the prohibition of claims on IF products. Overall, greater awareness that all IF products available on the market must meet certain standards and are therefore an appropriate infant food, might simplify 
the decision-making process for caregivers who are less experienced with purchasing IF and/or those who have the full range of IF products to choose from due to lack of dietary restrictions (e.g. allergies/intolerances).

In contrast to previous research showing that nutrition knowledge and social class impact use and understanding of nutrition information when choosing between general food products ${ }^{(28)}$, our findings suggest this association may not hold when choosing between IF products. Our study participants reported poor understanding of nutrition information, irrespective of education level and ethnicity. This suggests that any strategies for improving caregivers' ability to identify and meaningfully interpret differences between IF products should be aimed at all caregivers, rather than target specific sociodemographic subgroups.

Furthermore, the finding that caregivers feel that similarity of labelling information across IF products makes choice difficult, is of concern. This suggests current labelling information on IF products does not always provide caregivers with the information they require to feel better informed about a product, differentiate between products or make an informed purchase decision. Further, in some circumstances, information that is not easily understood by all consumers may work against its objective of informing consumers by undermining their confidence in the label/product ${ }^{(44,45)}$. Overall, this highlights a need to find more suitable means of communicating IF product information to consumers, to more effectively meet their information needs.

Research shows that the main sources from which women obtain nutrition/health information in pre- and postnatal periods are health-care providers, the media and the social environment ${ }^{(46-49)}$. While it is not known when caregivers commonly seek information regarding IF products, previous studies indicate that prenatal information focuses more on the birth process, rather than infant care ${ }^{(50-52)}$. Postnatally, health information is more frequently sought from online sources, rather than from personal health-care providers, whom some women perceive to provide repetitive and generalised information $^{(49,53,54)}$. Preferred sources of online information have been shown to vary and include more authoritative websites (provided by professional and academic organisations) as well as forums, blogs and social media ${ }^{(49)}$. Thus, personal health-care providers may play an important role in referring caregivers, who have made the decision to formula-feed, to reliable online information sources. However, further research in larger study samples is needed to determine the optimal timing of information provision (around how to select an appropriate IF product) as well as preferred information sources and formats/delivery modes.

A key strength of the present study is the relatively large sample size and range of geographic/sociodemographic subgroups investigated, including metropolitan and regional groups in both countries, PSE and SE subgroups in Australia, and Maori and other ethnicity subgroups in NZ. The differences in views/experiences found between subgroups suggests that the variety of subgroups used in the present study helped us obtain a broader range of views and experiences than might have been obtained otherwise (e.g. if conducting groups in a single geographical location or, potentially, with groups of caregivers heterogeneous in terms of education/ethnicity). Conducting discussions with educationally/ethnically similar caregivers may have also reduced social desirability bias and thus increased sharing of views and experiences. Study limitations to consider when interpreting the findings include the limited geographical reach, with data collection limited to two of eight Australian states/territories and the North Island in NZ. It is possible that different insights may have been generated had we purposefully sampled caregivers residing in other areas of Australian and NZ, or different population subgroups such as caregivers who are recent migrants/have a non-English speaking background and male caregivers. Finally, as the main aim of the study was to understand and explain rather than quantify perceptions and behaviours related to IF labelling, further quantitative research with larger samples of Australian and NZ caregivers would be required to obtain nationally representative data on the prevalence of different perceptions and behaviours; and to cross-validate the present study's findings.

\section{Conclusion}

The results of the present study indicate that caregivers, particularly first-time caregivers, require greater support with understanding labelling information on IF. Key challenges in addressing these issues in Australia and NZ are the specific regulatory and non-regulatory restrictions on labelling, presentation and marketing of IF products. The restrictions on how information is provided on labels and by health-care providers, and the absence of other forms of information (e.g. claims) mean that the mandated labelling information, particularly ingredient and nutrition information, needs to be clear and comprehensible to be effective. Further investigations are required to determine the most effective strategies for meeting information needs of consumers to enable easier identification and understanding of product differences. This is especially important given that the vast range of IF products across large price ranges in the market adds to the complexity of purchase decisions.

\section{Acknowledgements}

Acknowledgements: The authors wish to thank Dr Trevor Webb and Jenny Hazelton of FSANZ for their advice and comments on the manuscript, and Professor Wendy 
Umberger, Director of the Centre for Global Food and Resources, for contributions to the initial study design. Thanks also go to Anna Finizio for assisting with data collection. Financial support: This work was financially supported by FSANZ. FSANZ contributed to the design, analysis and writing of this article. Infrastructure support was provided by the University of Adelaide's Centre for Global Food and Resources. Conflict of interest: None. Authorship: L.M., H.F., G.D. and L.K. designed the research. L.M. coordinated data collection and analysed the data, and all authors interpreted the data. L.M. wrote first draft of paper which was revised by all authors. All authors read and approved the final manuscript. Ethics of buman subject participation: This study was conducted according to the guidelines laid down in the Declaration of Helsinki and all procedures involving human subjects were approved by the University of Adelaide Human Research Ethics Committee (approval number H-2016057). Written informed consent was obtained from all subjects.

\section{Supplementary material}

To view supplementary material for this article, please visit https://doi.org/10.1017/S1368980018003178

\section{References}

1. Australian Institute of Health and Welfare (2011) 2010 Australian National Infant Feeding Survey: Indicator Results. Canberra: AIHW; available at http://www.aihw.gov. au/publication-detail/?id=10737420927

2. Plunket (2017) Annual breastfeeding statistics 2016. http:// www.plunket.org.nz/news-and-research/research-fromplunket/plunket-breastfeeding-data-analysis/annual-breast feeding-statistics/ (accessed December 2017).

3. Organisation for Economic Co-operation and Development (2014) OECD Family Database. CO1.5: Breastfeeding Rates. Paris: OECD.

4. World Health Organization (1981) International Code of Marketing of Breast-Milk Substitutes. Geneva: WHO; available at http://www.who.int/nutrition/publications/code_ english.pdf

5. Food Standards Australia New Zealand (2015) Australia New Zealand Food Standards Code - Standard 2.9.1 Infant Formula Products. Canberra: Australian Government.

6. Food Standards Australia New Zealand (2014) Australia New Zealand Food Standards Code - Standard 2.9.1 Infant Formula Products. Canberra: Australian Government.

7. Commonwealth Department of Health and Ageing (2003) Marketing in Australia of Infant Formulas: Manufacturers and Importers Agreement 1992 (MAIF Agreement). http:// www.health.gov.au/internet/main/publishing.nsf/Content/ health-pubhlth-publicat-document-brfeed-maif_agreement. htm (accessed February 2018).

8. Infant Nutrition Council (2014) The Infant Nutrition Council Code of Practice for the Marketing of Infant Formula in New Zealand (INC Code of Practice). http://www.infantnu tritioncouncil.com/marketing-codes/code-in-new-zealand/ (accessed February 2018).
9. Food Standards Australia New Zealand (2016) Labelled composition available on the retail market in Australia and New Zealand. Appendix 1 to Supporting Document 1 Definitions and nutrient composition - Proposal P1028. Infant Formula. http://www.foodstandards.gov.au/code/ proposals/Documents/P1028-Consult-SD1-Appendix-1.pdf (accessed February 2018).

10. National Health and Medical Research Council (2012) Infant Feeding Guidelines Information for Health Workers. Canberra: Australian Government.

11. Ministry of Health (2014) Code of practice for health workers New Zealand. http://www.health.govt.nz/ourwork/who-code-nz/code-practice-health-workers (accessed February 2018).

12. Battersby S (2010) An evaluation of midwives' knowledge of formula feeding and their role in supporting mothers who formula feed their infants. J Fam Health Care 20, 192-197.

13. Smith SA (2010) Information seeking needs of mothers who bottle-feed their young infants: how the information seeking process affects them and what libraries can do to help them. Master's Thesis, Victoria University of Wellington.

14. Lee E \& Furedi F (2005) Mothers' Experience of, and Attitudes to, Using Infant Formula in the Early Months. Canterbury: School of Social Policy, Sociology and Social Research, University of Kent.

15. Yockney C \& Comfort V (2013) Understanding caregivers' perceptions and use of follow-up formula and toddler milks in New Zealand and Australia: a qualitative report. Prepared for the Ministry of Primary Industries; MPI Technical Paper no. 2013/44. http://www.foodsafety.govt.nz/elibrary/ industry/caregivers-perceptions-follow-up-formula-qualitative. pdf (accessed December 2017).

16. Smith J \& Blake M (2013) Infant food marketing strategies undermine effective regulation of breast-milk substitutes: trends in print advertising in Australia, 1950-2010. Aust NZJ Public Health 37, 337-344.

17. Tarrant RC, Sheridan-Pereira M, McCarthy RA et al. (2013) Mothers who formula feed: their practices, support needs and factors influencing their infant feeding decision. Child Care Pract 19, 78-94.

18. Labiner-Wolfe J, Fein SB \& Shealy KR (2008) Infant formulahandling education and safety. Pediatrics 122, Suppl. 2, S85-S90.

19. Winstanley A \& Cressey P (2008) Information Sources and Practices - Preparation of Powdered Infant Formula in New Zealand - Qualitative Research. Prepared as part of a New Zealand Food Safety Authority contract for scientific services. http://www.foodsafety.govt.nz/elibrary/industry/ powdered-infant-formula/ (accessed December 2017).

20. Food Standards Australia New Zealand (2016) Rapid evidence assessment on infant formula preparation, perceptions and label use. Attachment A2.2 to Supporting Document 2 - Safety \& Food Technology - Proposal P1028 Infant Formula. http://www.foodstandards.gov.au/code/ proposals/Documents/P1028-Consult-SD2-SafetyTechnology. pdf (accessed December 2017).

21. Miller LMS \& Cassady DL (2015) The effects of nutrition knowledge on food label use. A review of the literature. Appetite 92, 207-216.

22. Higginson CS, Kirk TR, Rayner M et al. (2002) How do consumers use nutrition label information? Nutr Food Sci 32, $145-152$.

23. Bialkova S \& van Trijp H (2010) What determines consumer attention to nutrition labels? Food Qual Prefer 21, 1042-1051.

24. Jacobs SA, de Beer H \& Larney M (2011) Adult consumers' understanding and use of information on food labels: a study among consumers living in the Potchefstroom and Klerksdorp regions, South Africa. Public Health Nutr 14, $510-522$ 
25. Hawley KL, Roberto CA, Bragg MA et al. (2013) The science on front-of-package food labels. Public Health Nutr 16, 430-439.

26. Drichoutis AC, Lazaridis P \& Nayga RM Jr (2006) Consumers' use of nutritional labels: a review of research studies and issues. Acad Market Sci Rev 9, 93-118.

27. Cowburn G \& Stockley L (2005) Consumer understanding and use of nutrition labelling: a systematic review. Public Health Nutr 8, 21-28.

28. Grunert KG, Fernández-Celemín L, Wills JM et al. (2010) Use and understanding of nutrition information on food labels in six European countries. J Public Health 18, 261-277.

29. Huang Y, Labiner-Wolfe J, Huang H et al. (2013) Association of health profession and direct-to-consumer marketing with infant formula choice and switching. Birth 40, 24-31.

30. Berry NJ, Jones S \& Iverson D (2010) It's all formula to me: women's understandings of toddler milk ads. Breastfeed Rev 18, 21-30.

31. Berry NJ, Jones SC \& Iverson D (2011) Relax, you're soaking in it: sources of information about infant formula. Breastfeed Rev 19, 9-18.

32. Morgan DL (1998) The Focus Group Guidebook. Thousand Oaks, CA: SAGE Publications, Inc.

33. Krueger RA (1988) Focus Groups: A Practical Guide for Applied Research. Thousand Oaks, CA: SAGE Publications, Inc.

34. Freeman T (2006) 'Best practice' in focus group research: making sense of different views. J Adv Nurs 56, 491-497.

35. Wu L, Yin S, Xu Y et al. (2014) Effectiveness of China's organic food certification policy: consumer preferences for infant milk formula with different organic certification labels. Can J Agric Econ 62, 545-568.

36. Huang Y, Li S, Mu Q et al. (2015) Consumption survey on infant formula in urban and suburb of Hohhot. China Dairy Ind 43, 53-58.

37. Tshikovhi MP, Gericke GJ \& Bekker PJ (2015) Factors that influenced mothers and/or caregivers in the Tshwane Metropolitan Municipality, South Africa, to purchase infant formula for their infants. S Afr J Clin Nutr 28, 6-11.

38. Gale NK, Heath G, Cameron E et al. (2013) Using the framework method for the analysis of qualitative data in multidisciplinary health research. BMC Med Res Methodol 13, 117.

39. Ritchie J \& Spencer L (1994) Qualitative data analysis for applied policy research. In Analysing Qualitative Data, pp. 173-194 [A Bryman and RG Burgess, editors]. London: Routledge.

40. Wallace LS, Rosenstein PF \& Gal N (2016) Readability and content characteristics of powdered infant formula instructions in the United States. Matern Child Health J 20, 889-894.

41. Burton S \& Andrews JC (1996) Age, product nutrition, and label format effects on consumer perceptions and product evaluations. J Consum Aff 30, 68-89.

42. TNS Social Research (2004) Consumer Research on the Need for Consistency in Nutrition Information Panels. A TNS Social Research Report prepared for Food Standards Australia New Zealand. Canberra: FSANZ.

43. Williams P (2005) Consumer understanding and use of health claims for foods. Nutr Rev 63, 256-264.

44. Salaün Y \& Flores K (2001) Information quality: meeting the needs of the consumer. Int I Inform Manage 21, 21-37.

45. Tonkin E, Webb T, Coveney J et al. (2016) Consumer trust in the Australian food system - the everyday erosive impact of food labelling. Appetite 103, 118-127.

46. Malek L, Umberger W, Makrides M et al. (2016) Poor adherence to folic acid and iodine supplement recommendations in preconception and pregnancy: a cross-sectional analysis. Aust N Z J Public Health 40, 424-429.

47. Bernhardt JM \& Felter EM (2004) Online pediatric information seeking among mothers of young children: results from a qualitative study using focus groups. $J$ Med Internet Res 6, e7.

48. Bianchi CM, Huneau J-F, Le Goff G et al. (2016) Concerns, attitudes, beliefs and information seeking practices with respect to nutrition-related issues: a qualitative study in French pregnant women. BMC Pregnancy Childbirth 16, 306.

49. Guerra-Reyes L, Christie VM, Prabhakar A et al. (2016) Postpartum health information seeking using mobile phones: experiences of low-income mothers. Matern Child Health J 20, 13-21.

50. McVeigh C (1997) Motherhood experiences from the perspective of first-time mothers. Clin Nurs Res 6, 335-348.

51. Moran CF, Holt VL \& Martin DP (1997) What do women want to know after childbirth? Birth 24, 27-34.

52. Sword W \& Watt S (2005) Learning needs of postpartum women: does socioeconomic status matter? Birth 32, 86-92.

53. Gibson L \& Hanson VL (2013) Digital motherhood: how does technology help new mothers? In CHI '13: Proceedings of the SIGCHI Conference on Human Factors in Computing Systems, pp. 313-322. New York: Association for Computing Machinery.

54. Jang J, Dworkin J \& Hessel H (2015) Mothers' use of information and communication technologies for information seeking. Cyberpsychol Behav Soc Netw 18, 221-227. 